\title{
Telomerase reverse transcriptase promoter mutation and its clinical implication in thyroid cancer
}

\section{Jae Hoon Chung}

Division of Endocrinology \& Metabolism, Department of Medicine and Thyroid Center, Samsung Medical Center, Sungkyunkwan University School of Medicine, Seoul, Korea

Received: January 31, 2018

Revised: March 4, 2018

Accepted: March 9, 2018

Corresponding author:

Jae Hoon Chung

Division of Endocrinology \& Metabolism, Department of Medicine and Thyroid Center, Samsung Medical Center, Sungkyunkwan University School of Medicine, 81 Irwonro, Gangnam-gu, Seoul 06351, Korea

Tel: +82-2-3410-3434

E-mail: thyroid@skku.edu
This is an Open Access article distributed under the terms of the Creative Commons Attribution Non-Commercial License (http:// creativecommons.org/licenses/ by-nc/4.0/).

\section{ABSTRACT}

Considering the long-term survival in most patients with thyroid cancer, it is very important to distinguish patients who need aggressive treatment from those who do not. Clinicopathological prognostic factors have been used to predict their prognoses, but they could not completely predict the final outcome of each patient. Recently, molecular marker-based risk stratification of thyroid cancer has been proposed to better estimate the risk. BRAF mutation has drawn much attention based on its high prevalence. However, its association with recurrence/mortality is not clear, and it is debatable. Telomerase reverse transcriptase (TERT) promoter mutation has been identified in over 50 human cancers including thyroid cancer after its first discovery in melanoma. It increases telomerase activity, which allows cancer cells to immortalize. It was found in approximately $10 \%$ of papillary thyroid carcinoma, $17 \%$ of follicular thyroid carcinoma, and $40 \%$ of poorly differentiated or anaplastic thyroid carcinoma. It is highly prevalent in old age, large tumors, aggressive histology, advanced stages, and distant metastasis. It is associated with increased recurrence and mortality. Concomitant TERT and BRAF mutations diminished the survival rate. Inclusion of TERT promoter mutation analysis with conventional clinicopathological evaluation could lead to better prognostication and management for individual patients.

Keywords: BRAF mutation; Mortality; Recurrence; Telomerase reverse transcriptase promoter mutation; Thyroid neoplasms

\section{INTRODUCTION}

Thyroid cancer is the most common endocrine malignancy, and its incidence is on the rise in the world [1-4]. This is mainly due to the early detection of papillary thyroid carcinoma (PTC) less than $1 \mathrm{~cm}$ in diameter with a high-resolution ultrasonography (USG) [5,6]. However, the incidence of larger thyroid cancers is also increasing [1,2]. Many experts emphasized that its early detection cannot completely explain the observed increase in thyroid cancer $[2,7]$. Therefore, other possible explanations should be explored. The major contribution of genetic factors 
to the pathogenesis of thyroid cancer has been revealed [8]. The population living in East Asia, including Korea, has been reported to be genetically susceptible to thyroid cancer $[9,10]$. Extremely high iodine intake, increased exposure to medical radiation, and rising rates of obesity are also potential candidates to explain this phenomenon [11-16]. Jung et al. [17] reported the prediction of thyroid cancer incidence and mortality in Korea in 2017. A total of 23,862 new thyroid cancer cases (crude incidence 46.2/100,000, age-standardized incidence $33.8 / 100,000$ ) and 360 cancer-specific deaths are expected to occur in Korea in 2017. Thyroid cancer is the fourth most common cancer after colorectum, stomach, and lung cancer in Korea.

PTC and follicular thyroid carcinoma (FTC) referred together as differentiated thyroid carcinoma (DTC). It accounts for more than $90 \%$ in all thyroid cancers, and it has a favorable prognosis $[18,19]$. However, patients with poorly-differentiated thyroid carcinoma (PDTC) or anaplastic thyroid carcinoma (ATC), and patients who present with advanced stage or distant metastasis have poor prognoses [20-25]. Considering the long-term survival in most patients with DTC, it is very important to distinguish patients who need aggressive treatment from those who do not. Precise identification of risk factors for high mortality can make an optimal therapeutic strategy in each patient. Clinicopathological prognostic factors, such as age, histological type, tumor size, local invasion, lymph node metastasis, and distant metastasis, have been used to predict their prognoses [26,27]. However, they could not completely predict the final outcome of each patient [28].

\section{PROGRESS IN MOLECULAR MECHANISM OF THYROID CANCER}

Molecular tests for genetic alterations and different gene expressions in thyroid cancer may enhance the diagnostic value of cytologic examination and predictability of clinical outcomes [29]. Molecular changes precede histological changes [30]. Gupta et al. [30] described heterogeneous histological changes in a tumor: (1) microfollicular areas with well-developed nuclear features of PTC, (2) areas composed of larger follicles with borderline nuclear features of PTC, and (3) areas with large follicles lacking nuclear features of PTC. When tested separately, all three areas were positive for the same NRAS61 mutation.

Most progress has been made in elucidating the molecular mechanisms involved in the pathogenesis of thyroid cancer after the detection of RAS mutation and RET/PTC rearrangement. Newly identified oncogenes have provided the basic information upon which new diagnostic tools and new prognostic markers, as well as new targeted agents, have been developed. The Cancer Genome Atlas (TCGA) study presented integrated genomic characterization of PTC in 2014 [31]. It described the low frequency of somatic alterations in 496 PTCs compared to other cancers. It reduced the fraction of PTC cases with unknown oncogenic driver from $25 \%$ to $3.5 \%$. Genetic alterations in thyroid cancer included point mutations ( $75 \%)$, gene fusions (15\%), and copy number variations (7\%). In patients with an advanced stage, tumors may have more than one mutation; therefore, the overall mutation burden exceeds $100 \%$. The frequency of the main drivers (BRAF, RAS, and RET) sums to less than $100 \%$ because in some cases the drivers are not known or they are lower frequency events [32].

RAS genes (HRAS, KRAS, and NRAS) are G proteins that signal to both the mitogen-activated protein kinase (MAPK) and phosphatidylinositol-3 kinase (PI3K)/AKT pathways. RAS mutations typically occur in codons 12,13 , and 61 , and are found in $20 \%$ to $40 \%$ of follicular adenoma, $40 \%$ to $50 \%$ of FTC, and in $10 \%$ to $20 \%$ of follicular variant PTC [33-36]. In contrast, mutations in HRAS and KRAS also occur in medullary thyroid cancer (MTC) [37]. The RET gene is a receptor tyrosine kinase that is expressed in parafollicular $C$ cells, but not in follicular cells. The RET proto-oncogene in PTC is activated by chromosomal rearrangement. It is rearranged by the fusion of the tyrosine kinase domain of RET gene and the 5 ' end sequence of a non-oncogenic gene, which is expressed in follicular cells $[38,39]$. An intrachromosomal rearrangement generates the chimeric oncogene, which has been designated as RET/PTC. The most common types are RET/PTC1 (formed by fusion of RET with the CCDC6 [coiled-coil domaincontaining protein 6] gene) and RET/PTC3 (formed by fusion of RET with the NCOA4 [nuclear receptor coactivator 4] gene) $[38,39]$. RET/PTC rearrangements are highly prevalent in children, young adults, and patients with a history of radiation exposure [40]. In addition, the RET gene mutation is commonly found in MTC [41-43]. Germline mutations of the RET proto-oncogene in hereditary MTC were identified in 1993 and 1994 [41-43]. Mutation analysis of the RET proto-oncogene has been established as a screening procedure, and every patient with MTC, as well as family members of RET-positive patients with MTC, should undergo mutation analysis [44]. Recently, genotype-phenotype correlations of hereditary MTC have been reported. 
Mutations of the BRAF gene were first identified in human cancer in 2002 [45]. Thereafter, more than 40 mutations of the $B R A F$ gene have been discovered. Most cases activating the $B R A F$ mutation involve codon 600 and result in the $\mathrm{V} 600 \mathrm{E}$ mutation, and a few cases of other BRAF mutations occur as $\mathrm{K} 601 \mathrm{E}$ mutation, small in-frame insertions, deletions, or rearrangement $[46,47]$. The mutations of the BRAF gene were frequently detected in thyroid cancer [47-52]. The thymine-toadenine transversion at nucleotide position 1799 in exon 15 of the BRAF gene results in a valine-to-glutamate substitution at residue 600 , which leads to constitutive activation of MAPK signaling downstream $[51,53]$. The prevalence of the $B R A F^{V 600 E}$ mutation in PTC ranges from $30 \%$ to $80 \%$, depending on the iodine status and geographic location [54-56]. The $B R A F^{\mathrm{V} 600 \mathrm{E}}$ mutation is known to be highly specific to PTC [57]. In Korea, approximately $97 \%$ of newly diagnosed thyroid cancer is PTC and $80 \%$ of PTC cases harbor the BRAF ${ }^{\mathrm{V} 600 \mathrm{E}}$ mutation. Therefore, molecular testing for the $B R A F^{1600 E}$ mutation in cytologic specimen increases diagnostic sensitivity and accuracy in a $B R A F^{\mathrm{V} 600 \mathrm{E}}$ mutation-prevalent population [58,59]. Most studies have demonstrated that the BRAF mutation is significantly associated with one or more high-risk clinicopathological characteristics of PTC, such as extrathyroidal extension, lymph node metastasis, and advanced stages [50,60-62].

The PAX8 (paired-box gene 8)/peroxisome proliferator-activated receptor $Y$ (PPAR $\gamma$ ) rearrangement, a fusion between a paired domain transcription factor and the PPAR genes, is found in $30 \%$ to $40 \%$ of FTC, and infrequently in the follicular adenoma or follicular variant PTC [63-65]. Mutations in TP53 (tumor protein p53) are frequently detected in ATC. Mutations of EIF1AX (eukaryotic translation initiation factor $1 \mathrm{~A}$, $X$-linked), a component of the translation preinitiation complex, are infrequent and are mutually exclusive with other driver mutations in PTC [66].

\section{THE SIGNALING PATHWAYS INVOLVED IN THYROID CARCINOGENESIS}

The main signaling pathways involved in thyroid carcinogenesis are the MAPK and PI3K/AKT pathways. They regulate multiple cell processes including proliferation, differentiation, and survival. The MAPK pathway is frequently activated in thyroid cancer through the BRAF mutation, RAS mutation, and the RET/PTC rearrangement [47,51]. It is a common initiating event in DTC. Mutations involving the PI3K/AKT pathway are found more frequently in FTC and dedifferentiated types of thyroid carcinoma. ATC has mutations in gene encoding components of the PI3K/AKT/mTOR (mammalian tar- get of rapamycin) pathway and of the proteins involved in epigenetic regulation, whereas PDTC has an intermediate frequency of these events.

\section{MOLECULAR MARKER-BASED RISK STRATIFICATION OF THYROID CANCER}

Molecular marker-based risk stratification of thyroid cancer has been recently proposed for estimation of risk [67]. The $B R A F$ mutation has drawn much attention based on its high prevalence, occurring in about $30 \%$ to $80 \%$ of PTC and $25 \%$ of ATC cases [54-56,61,68]. In 2012, Tufano et al. [69] published a meta-analysis from 14 studies including 2,470 PTC patients. They demonstrated that the BRAF mutation in PTC was significantly associated with PTC recurrence, lymph node metastasis, extrathyroidal extension, and advanced stages. In 2013, Xing et al. [70] reported the association of the $B R A F$ mutation with mortality in a large multicenter study of 1,849 PTC patients. They demonstrated that the BRAF mutation was associated with an increased cancer-related mortality, but it was no longer significant after the adjustment of risk factors, such as lymph node metastasis, extrathyroidal invasion, and distant metastasis. However, many studies from Korea, Taiwan, and Japan demonstrated that the BRAF mutation was not associated with disease-free survival as well as poor prognostic factors [71-73]. In addition, many physicians wonder why thyroid cancer-related mortality is still low, although the BRAF mutation is highly prevalent. These findings suggest that the BRAF mutation taken in isolation may be a relatively sensitive, but not a specific marker of tumor recurrence and tumor-related mortality. Recently, more specific markers predictive of aggressive behavior have emerged. In patients with an advanced stage, tumors may have more than one mutation. Next generation sequencing-based analysis revealed that some PTCs have more than one mutation, and these have aggressive behavior [74].

\section{TELOMERASE REVERSE TRANSCRIP- TASE PROMOTER MUTATION IN THY- ROID CANCER}

\section{Telomere and telomerase}

Telomeres are located at the ends of linear chromosomes. They are composed of hundreds to thousands of tandem DNA repeat sequences: hexameric TTAGGG in the leading strand and CCCTAA in the lagging strand in humans. They were coated by protective proteins termed 'shelterin.' The 3 ' 
end of the telomeric leading strand terminates as a single-stranded overhang, which folds back and invades the double-stranded telomeric helix, forming the T loop. Telomeres can be directly visualized under the microscope at the ends of metaphase chromosomes by fluorescence in situ hybridization (FISH). The average telomere length can be measured by several methods: a technique that combines flow cytometry and FISH (flow-FISH), Southern blotting, and a quantitative polymerase chain reaction assay. The average length of telomeres in human leukocytes varies, ranging from approximately $11 \mathrm{~kb}$ at birth (in umbilical-cord blood) to $6 \mathrm{~kb}$ at 90 years of age. Telomere loss is most rapid early in life, and over a lifespan, it is not linear but follows a third-order polynomial [75]. The normal cell will divide between 50 to 70 times before cell death (Hayflick limit). As the cell divides, the telomeres get smaller. Because of the telomeres shortening through each division, the telomeres will eventually no longer be present on the chromosome. The cells finally become senescent and cell division stops. Shortened telomeres impair immune functions that might also increase cancer susceptibility [76]. Therefore, telomere shortening can be related to the risk of cancer.

Telomerase is a reverse transcriptase that utilizes an RNA template to add telomeric repeats to the 3 ' ends of chromosomes. Telomerase consists of some molecules each of telomerase reverse transcriptase (TERT), telomerase RNA, and dyskerin. It protects the telomere repeats from erosion, such as DNA damage or fusion with neighboring chromosomes. Therefore, it reverses telomere shortening. Telomerase is not expressed in most normal cells, but it is frequently activated in most cancer cells as well as normal stem cells $[77,78]$.

\section{TERT promoter mutation in cancer}

Cancer cells are immortal because activated telomerase allows them to survive much longer than normal cells. Therefore, the maintenance of telomere length is very important for immortalization of cancer cells. In 2013, the point mutations of TERT promoter were first found in melanoma, and these somatic mutations enhanced promoter activity by two- to four-fold, which could immortalize cancer cells by maintaining telomere length [79-81]. Somatic mutations in the TERT promoter have been identified in over 50 human cancers, including thyroid cancer [82]. TERT promoter mutation has been shown to increase telomerase activity, which protects the telomere repeats from erosion and maintains the telomere length. Two mutations in the TERT promoter (chr5:1295228C > T, termed C228T, and chr5:1295250C > T, termed C250T) were discovered in melanoma $[79,80]$.

\section{TERT promoter mutation in thyroid cancer}

The C228T and C250T TERT promoter mutations were detected in follicular cell-derived thyroid cancer, but they were absent in benign lesions and MTC [82-86]. These two TERT promoter mutations occurred in a mutually exclusive manner. C228T is far more dominant than C250T. The mutual exclusivity of the two TERT promoter mutations suggests that either may function sufficiently to play an important role in thyroid tumorigenesis although which one is more powerful oncogenically has not been established at this time [87]. In meta-analysis, TERT promoter mutation was found in approximately $10 \%$ of PTC, $17 \%$ of FTC, and $40 \%$ of PDTC/ATC [88,89]. Among PTC, it was more prevalent in tall cell variants than conventional or follicular variants. The TERT promoter mutation has a significantly higher prevalence in old age, large tumors, aggressive histology, advanced stages, and distant metastasis $[88,89]$. Why it is more prevalent in old age? A normal thyroid epithelial cell from young age is telomerase proficient with a longer telomere, whereas that from an old age is telomerase deficient with a shorter telomere. When it is attacked by oncogenic events, it undergoes active proliferation with further erosion of its telomere. In that case, telomere dysfunction or even telomere crisis occurs in old age because of its initial shorter telomere and lack of telomerase activity. Telomere crisis triggers both genomic instability and telomerase activation: TERT promoter mutation is thus the consequence of genomic instability, whereas in turn, it contributes to derepressing TERT transcription and telomerase activation [85]. TERT promoter mutation has not been found in childhood thyroid cancer, except for one case in Saudi Arabia [90-93]. BRAF mutation has been known to be associated with iodine intake, but TERT promoter mutation is not [94]. In a multivariate comparison between the PTC with and without anaplastic transformation, TERT promoter mutation was independently associated with anaplastic transformation [95]. Collectively, PTC-derived anaplastic carcinomas are characterized by BRAF and TERT promoter mutations, and these mutations occur prior to anaplastic transformation. Of note, a PTC harboring TERT promoter mutation is at higher risk for anaplastic transformation. Interestingly, TERT mutations in some studies were found to be more common in tumors with a $B R A F^{1600 E}$ mutation, which may suggest a possible synergistic interplay between MAPK pathway activation and telomerase activation to promote aggressive tumor behavior $[83,84]$. TERT promoter mutation, as well as BRAF mu- 
tation, is known to be associated with tumor recurrence, but a secondary recurrence rate is significantly higher in patients with a TERT promoter mutation, not a BRAF mutation [96]. In meta-analysis including 11 studies with 3,911 patients, PTC with concurrent BRAF and TERT promoter mutations were associated with increased tumor aggressiveness and had the worst prognosis in comparison with PTCs harboring BRAF or TERT promoter mutation alone $[97,98]$. The genotype of primary tumors has a high concordance with the genotype of lymph node metastasis. Distant metastases show an enrichment of TERT promoter mutations and a decrease in BRAF mutations. Therefore, TERT promoter mutations may play a role in distant metastases [99]. The TERT promoter mutation is also associated with increased mortality in PTC, as well as other thyroid cancers. Liu et al. [100] reported that PTC with concurrent BRAF and TERT promoter mutations were associated with increased cancer-specific mortality in comparison with PTCs harboring BRAF or TERT promoter mutation alone (TERT/BRAF $22.7 \%$ vs. TERT $6.3 \%$ vs. BRAF $2.4 \%$ vs. wild type 0.6\%). Kim et al. [89] evaluated the association of a TERT promoter mutation with the survival of 409 thyroid cancer patients followed for a median of 13 years. They reported that the TERT promoter mutation was independently associated with poorer overall survival in patients with DTC (10-year survival rate, $66.2 \%$ vs. $98.3 \%$ for wild type) and in patients with PTC (74.2\% vs. $99.3 \%)$. Concomitant TERT and BRAF mutations diminished the survival rate of patients with PTC.

\section{Clinical implication of TERT promoter mutation in thyroid cancer}

Hahn et al. [98] and Kim et al. [101] investigated the association of BRAF and TERT promoter mutations with USG findings. They reported that PTC with no mutation, PTC with BRAF mutation alone, and PTC with both BRAF and TERT promoter mutations increased linearly in the probability of displaying malignant USG features [98]. They, also, reported that PTC with TERT promoter mutation could be suggested by the USG findings of nonparallel orientation and microlobulated margin, especially in patients older than 50 years [101].

Wang et al. [102] reported an interesting observation in 2014. They identified a TERT promoter mutation (C228T) in 1 out of 58 follicular adenoma postoperatively. The patient with the C228T mutated follicular adenoma later developed a scar recurrence and died of FTC, whereas none of the remaining 57 patients with follicular adenoma had a recurrence. Therefore, they concluded that TERT promoter muta- tions might occur as an early genetic event in thyroid follicular tumors that have not developed malignant features on routine histopathological workup. According to this finding, physicians should make aggressive therapeutic strategies in patients with a TERT promoter mutation. At least, a total thyroidectomy should be conducted in patients with a TERT promoter mutation, even though they were diagnosed with follicular neoplasm by cytologic examination.

Xu et al. [103] also reported an interesting finding in 2017. They observed 15 cases with low-risk histology with distant metastases at present. The majority were encapsulated follicular variants of PTC with capsular invasion only. Among eight tumors that were subjected to next-generation sequencing analysis, TERT promoter mutation was highly prevalent. TERT promoter mutations occurred at a higher rate than that seen in PTC in general and may help explain the aggressive behavior. DTC with low-risk histologic features and distant metastasis was a rare occurrence, accounting for less than $3 \%$ of metastatic non-ATC. When finding DTC cases with low-risk histology together with distant metastasis, distant metastasis is almost always found at present. These tumors might have a high probability to have TERT promoter mutations.

In 2015, the American Thyroid Association introduced new therapeutic guidelines for DTC and included the reclassification of cancer recurrence risk after initial treatment [104]. The new dynamic risk stratification (DRS) system can predict the structural recurrence with higher accuracy than a traditional predictive system based on clinicopathologic information [105]. Kim et al. [106] aimed to refine the risk prediction for structural recurrence and cancer-specific mortality using the TERT promoter mutation in 357 DTC patients without initial distant metastasis with long-term follow-up (median, 14 years). They developed an integrative prognostic system that incorporates TERT promoter mutation into the recently proposed DRS system after initial therapy to better categorize and predict outcomes. Cox regression was used to calculate adjusted hazard ratios (AHRs) to derive AHR groups. Patients in higher AHR groups were significantly at higher risk of recurrence and cancer-related death. The proportion of variance explained (PVE) of the AHR system to predict recurrence was higher than the DRS system ( $22.4 \%$ vs. $18.5 \%)$. PVE of the AHR system to predict cancer-related death was also higher than the TNM (tumor, node, metastasis) system (11.5\% vs. $7.4 \%)$. They concluded that the inclusion of TERT promoter mutation analysis with conventional clinicopathological evaluation could lead to better prognostication and 
management for individual patients.

\section{CONCLUSION}

Considering the long-term survival in most patients with thyroid cancer, it is very important to distinguish patients who need aggressive treatment from those who do not. Conventional clinicopathological prognostic factors could not completely predict the final outcome of each patient. Although the BRAF mutation has drawn much attention, there are limitations to predict the clinical outcome of each patient. TERT promoter mutation has been found in $10 \%$ to $20 \%$ of DTC and $40 \%$ of dedifferentiated thyroid cancer. Although it is highly prevalent in old age, large tumors, aggressive histology, advanced stages, and distant metastasis, it is strongly associated with tumor recurrence and mortality in thyroid cancer. Therefore, the inclusion of TERT promoter mutation analysis with conventional clinicopathological evaluation could lead to better prognostication and management for individual patients.

\section{CONFLICTS OF INTEREST}

No potential conflict of interest relevant to this article was reported.

\section{ORCID}

Jae Hoon Chung https://orcid.org/0000-0002-9563-5046

\section{REFERENCES}

1. Chen AY, Jemal A, Ward EM. Increasing incidence of differentiated thyroid cancer in the United States, 19882005. Cancer 2009;115:3801-7.

2. Enewold L, Zhu K, Ron E, Marrogi AJ, Stojadinovic A, Peoples GE, et al. Rising thyroid cancer incidence in the United States by demographic and tumor characteristics, 1980-2005. Cancer Epidemiol Biomarkers Prev 2009;18: 784-91.

3. Ahn HS, Kim HJ, Welch HG. Korea's thyroid-cancer "epidemic": screening and overdiagnosis. N Engl J Med 2014; 371:1765-7.

4. Jung KW, Won YJ, Oh CM, Kong HJ, Lee DH, Lee KH, et al. Cancer statistics in Korea: incidence, mortality, survival, and prevalence in 2014. Cancer Res Treat 2017;49:292305.
5. Udelsman R, Zhang Y. The epidemic of thyroid cancer in the United States: the role of endocrinologists and ultrasounds. Thyroid 2014;24:472-9.

6. Shin S, Park SE, Kim SY, Hyun MK, Kim SW, Kwon JW, et al. Effectiveness of ultrasonographic screening for thyroid cancer: round-table conference in the National Evidence-based Healthcare Collaborating Agency (NECA) in conjunction with the Korean Thyroid Association. Asian Pac J Cancer Prev 2014;15:5107-10.

7. Chung JH. Unfounded reports on thyroid cancer. J Korean Med Sci 2014;29:1033-4.

8. Czene K, Lichtenstein P, Hemminki K. Environmental and heritable causes of cancer among 9.6 million individuals in the Swedish Family-Cancer Database. Int J Cancer 2002;99:260-6.

9. Mousavi SM, Brandt A, Sundquist J, Hemminki K. Risks of papillary and follicular thyroid cancer among immigrants to Sweden. Int J Cancer 2011;129:2248-55.

10. Magreni A, Bann DV, Schubart JR, Goldenberg D. The effects of race and ethnicity on thyroid cancer incidence. JAMA Otolaryngol Head Neck Surg 2015;141:319-23.

11. Williams ED, Doniach I, Bjarnason O, Michie W. Thyroid cancer in an iodide rich area: a histopathological study. Cancer 1977;39:215-22.

12. Goodman MT, Yoshizawa CN, Kolonel LN. Descriptive epidemiology of thyroid cancer in Hawaii. Cancer 1988; 61:1272-81.

13. Burgess JR, Dwyer T, McArdle K, Tucker P, Shugg D. The changing incidence and spectrum of thyroid carcinoma in Tasmania (1978-1998) during a transition from iodine sufficiency to iodine deficiency. J Clin Endocrinol Metab 2000;85:1513-7.

14. Ron E, Kleinerman RA, Boice JD Jr, LiVolsi VA, Flannery JT, Fraumeni JF Jr. A population-based case-control study of thyroid cancer. J Natl Cancer Inst 1987;79:1-12.

15. Boltze C, Brabant G, Dralle H, Gerlach R, Roessner A, Hoang-Vu C. Radiation-induced thyroid carcinogenesis as a function of time and dietary iodine supply: an in vivo model of tumorigenesis in the rat. Endocrinology 2002; 143: 2584-92.

16. Ahn YS, Park RM, Koh DH. Cancer admission and mortality in workers exposed to ionizing radiation in Korea. $J$ Occup Environ Med 2008;50:791-803.

17. Jung KW, Won YJ, Oh CM, Kong HJ, Lee DH, Lee KH. Prediction of cancer incidence and mortality in Korea, 2017. Cancer Res Treat 2017;49:306-12.

18. Mazzaferri EL, Jhiang SM. Long-term impact of initial 
surgical and medical therapy on papillary and follicular thyroid cancer. Am J Med 1994;97:418-28.

19. Hundahl SA, Fleming ID, Fremgen AM, Menck HR. A National Cancer Data Base report on 53,856 cases of thyroid carcinoma treated in the U.S., 1985-1995 [see commetns]. Cancer 1998;83:2638-48.

20. Volante M, Landolfi S, Chiusa L, Palestini N, Motta M, Codegone $A$, et al. Poorly differentiated carcinomas of the thyroid with trabecular, insular, and solid patterns: a clinicopathologic study of 183 patients. Cancer 2004;100: 950-7.

21. Jung TS, Kim TY, Kim KW, Oh YL, Park DJ, Cho BY, et al. Clinical features and prognostic factors for survival in patients with poorly differentiated thyroid carcinoma and comparison to the patients with the aggressive variants of papillary thyroid carcinoma. Endocr J 2007; 54:265-74.

22. Mohebati A, Dilorenzo M, Palmer F, Patel SG, Pfister D, Lee N, et al. Anaplastic thyroid carcinoma: a 25-year single-institution experience. Ann Surg Oncol 2014;21: 1665-70.

23. Ito Y, Higashiyama T, Takamura Y, Kobayashi K, Miya A, Miyauchi A. Clinical outcomes of patients with papillary thyroid carcinoma after the detection of distant recurrence. World J Surg 2010;34:2333-7.

24. Nixon IJ, Whitcher MM, Palmer FL, Tuttle RM, Shaha AR, Shah JP, et al. The impact of distant metastases at presentation on prognosis in patients with differentiated carcinoma of the thyroid gland. Thyroid 2012;22:884-9.

25. Sohn SY, Kim HI, Kim YN, Kim TH, Kim SW, Chung JH. Prognostic indicators of outcomes in patients with lung metastases from differentiated thyroid carcinoma during long-term follow-up. Clin Endocrinol (Oxf) 2018; 88:318-26.

26. DeGroot LJ, Kaplan EL, McCormick M, Straus FH. Natural history, treatment, and course of papillary thyroid carcinoma. J Clin Endocrinol Metab 1990;71:414-24.

27. Mazzaferri EL, Kloos RT. Clinical review 128: current approaches to primary therapy for papillary and follicular thyroid cancer. J Clin Endocrinol Metab 2001;86:144763.

28. Hay ID, Bergstralh EJ, Goellner JR, Ebersold JR, Grant CS. Predicting outcome in papillary thyroid carcinoma: development of a reliable prognostic scoring system in a cohort of 1779 patients surgically treated at one institution during 1940 through 1989. Surgery 1993;114:10507.
29. Schmitt FC, Longatto-Filho A, Valent A, Vielh P. Molecular techniques in cytopathology practice. J Clin Pathol 2008; 61:258-67.

30. Gupta N, Dasyam AK, Carty SE, Nikiforova MN, Ohori NP, Armstrong M, et al. RAS mutations in thyroid FNA specimens are highly predictive of predominantly low-risk follicular-pattern cancers. J Clin Endocrinol Metab 2013; 98:E914-22.

31. Cancer Genome Atlas Research Network. Integrated genomic characterization of papillary thyroid carcinoma. Cell 2014;159:676-90.

32. Fagin JA, Wells SA Jr. Biologic and clinical perspectives on thyroid cancer. N Engl J Med 2016;375:1054-67.

33. Lemoine NR, Mayall ES, Wyllie FS, Williams ED, Goyns M, Stringer B, et al. High frequency of ras oncogene activation in all stages of human thyroid tumorigenesis. Oncogene 1989;4:159-64.

34. Suarez HG, du Villard JA, Severino M, Caillou B, Schlumberger $\mathrm{M}$, Tubiana $\mathrm{M}$, et al. Presence of mutations in all three ras genes in human thyroid tumors. Oncogene 1990; 5:565-70.

35. Namba H, Rubin SA, Fagin JA. Point mutations of ras oncogenes are an early event in thyroid tumorigenesis. Mol Endocrinol 1990;4:1474-9.

36. Zhu Z, Gandhi M, Nikiforova MN, Fischer AH, Nikiforov YE. Molecular profile and clinical-pathologic features of the follicular variant of papillary thyroid carcinoma. An unusually high prevalence of ras mutations. Am J Clin Pathol 2003;120:71-7.

37. Agrawal N, Jiao Y, Sausen M, Leary R, Bettegowda C, Roberts NJ, et al. Exomic sequencing of medullary thyroid cancer reveals dominant and mutually exclusive oncogenic mutations in RET and RAS. J Clin Endocrinol Metab 2013;98:E364-9.

38. Grieco M, Santoro M, Berlingieri MT, Melillo RM, Donghi R, Bongarzone I, et al. PTC is a novel rearranged form of the ret proto-oncogene and is frequently detected in vivo in human thyroid papillary carcinomas. Cell 1990;60:55763.

39. Santoro M, Dathan NA, Berlingieri MT, Bongarzone I, Paulin C, Grieco M, et al. Molecular characterization of RET/ PTC3; a novel rearranged version of the RETproto-oncogene in a human thyroid papillary carcinoma. Oncogene 1994;9:509-16.

40. Nikiforov YE, Rowland JM, Bove KE, Monforte-Munoz H, Fagin JA. Distinct pattern of ret oncogene rearrangements in morphological variants of radiation-induced 
and sporadic thyroid papillary carcinomas in children. Cancer Res 1997;57:1690-4.

41. Donis-Keller H, Dou S, Chi D, Carlson KM, Toshima K, Lairmore TC, et al. Mutations in the RET proto-oncogene are associated with MEN 2A and FMTC. Hum Mol Genet 1993; 2:851-6.

42. Mulligan LM, Kwok JB, Healey CS, Elsdon MJ, Eng C, Gardner E, et al. Germ-line mutations of the RET proto-oncogene in multiple endocrine neoplasia type 2A. Nature 1993;363:458-60.

43. Hofstra RM, Landsvater RM, Ceccherini I, Stulp RP, Stelwagen T, Luo Y, et al. A mutation in the RET proto-oncogene associated with multiple endocrine neoplasia type 2B and sporadic medullary thyroid carcinoma. Nature 1994;367:375-6.

44. American Thyroid Association Guidelines Task Force, Kloos RT, Eng C, Evans DB, Francis GL, Gagel RF, et al. Medullary thyroid cancer: management guidelines of the American Thyroid Association. Thyroid 2009;19:565612.

45. Davies H, Bignell GR, Cox C, Stephens P, Edkins S, Clegg S, et al. Mutations of the BRAF gene in human cancer. Nature 2002;417:949-54.

46. Garnett MJ, Marais R. Guilty as charged: B-RAF is a human oncogene. Cancer Cell 2004;6:313-9.

47. Soares P, Trovisco V, Rocha AS, Lima J, Castro P, Preto A, et al. BRAF mutations and RET/PTC rearrangements are alternative events in the etiopathogenesis of PTC. Oncogene 2003;22:4578-80.

48. Cohen Y, Xing M, Mambo E, Guo Z, Wu G, Trink B, et al. BRAF mutation in papillary thyroid carcinoma. J Natl Cancer Inst 2003;95:625-7.

49. Fukushima T, Suzuki S, Mashiko M, Ohtake T, Endo Y, Takebayashi Y, et al. BRAF mutations in papillary carcinomas of the thyroid. Oncogene 2003;22:6455-7.

50. Namba H, Nakashima M, Hayashi T, Hayashida N, Maeda S, Rogounovitch TI, et al. Clinical implication of hot spot BRAF mutation, V599E, in papillary thyroid cancers. J Clin Endocrinol Metab 2003;88:4393-7.

51. Kimura ET, Nikiforova MN, Zhu Z, Knauf JA, Nikiforov YE, Fagin JA. High prevalence of BRAF mutations in thyroid cancer: genetic evidence for constitutive activation of the RET/PTC-RAS-BRAF signaling pathway in papillary thyroid carcinoma. Cancer Res 2003;63:1454-7.

52. Xu X, Quiros RM, Gattuso P, Ain KB, Prinz RA. High prevalence of BRAF gene mutation in papillary thyroid carcinomas and thyroid tumor cell lines. Cancer Res 2003;63:
4561-7.

53. Melillo RM, Castellone MD, Guarino V, De Falco V, Cirafici AM, Salvatore G, et al. The RET/PTC-RAS-BRAF linear signaling cascade mediates the motile and mitogenic phenotype of thyroid cancer cells. J Clin Invest 2005;115: 1068-81.

54. Xing M. BRAF mutation in papillary thyroid cancer: pathogenic role, molecular bases, and clinical implications. Endocr Rev 2007;28:742-62.

55. Guan H, Ji M, Bao R, Yu H, Wang Y, Hou P, et al. Association of high iodine intake with the T1799A BRAF mutation in papillary thyroid cancer. J Clin Endocrinol Metab 2009;94:1612-7.

56. Jung CK, Im SY, Kang YJ, Lee H, Jung ES, Kang CS, et al. Mutational patterns and novel mutations of the BRAF gene in a large cohort of Korean patients with papillary thyroid carcinoma. Thyroid 2012;22:791-7.

57. Nikiforov YE, Steward DL, Robinson-Smith TM, Haugen BR, Klopper JP, Zhu Z, et al. Molecular testing for mutations in improving the fine-needle aspiration diagnosis of thyroid nodules. J Clin Endocrinol Metab 2009;94: 2092-8.

58. Kim SK, Kim DL, Han HS, Kim WS, Kim SJ, Moon WJ, et al. Pyrosequencing analysis for detection of a BRAFV600E mutation in an FNAB specimen of thyroid nodules. Diagn Mol Pathol 2008;17:118-25.

59. Kim SW, Lee JI, Kim JW, Ki CS, Oh YL, Choi YL, et al. BRAFV600E mutation analysis in fine-needle aspiration cytology specimens for evaluation of thyroid nodule: a large series in a BRAFV600E-prevalent population. J Clin Endocrinol Metab 2010;95:3693-700.

60. Nikiforova MN, Kimura ET, Gandhi M, Biddinger PW, Knauf JA, Basolo F, et al. BRAF mutations in thyroid tumors are restricted to papillary carcinomas and anaplastic or poorly differentiated carcinomas arising from papillary carcinomas. J Clin Endocrinol Metab 2003;88: 5399-404.

61. Kim TH, Park YJ, Lim JA, Ahn HY, Lee EK, Lee YJ, et al. The association of the BRAF(V600E) mutation with prognostic factors and poor clinical outcome in papillary thyroid cancer: a meta-analysis. Cancer 2012;118:1764-73.

62. Lee JI, Jang HW, Kim SW, Kim JW, Oh YL, Chung JH. BRAFV600E mutation in fine-needle aspiration aspirates: association with poorer prognostic factors in larger papillary thyroid carcinomas. Head Neck 2013;35:548-53.

63. Marques AR, Espadinha C, Catarino AL, Moniz S, Pereira T, Sobrinho LG, et al. Expression of PAX8-PPAR gamma 1 
rearrangements in both follicular thyroid carcinomas and adenomas. J Clin Endocrinol Metab 2002;87:3947-52.

64. Nikiforova MN, Biddinger PW, Caudill CM, Kroll TG, Nikiforov YE. PAX8-PPARgamma rearrangement in thyroid tumors: RT-PCR and immunohistochemical analyses. Am J Surg Pathol 2002;26:1016-23.

65. Dwight T, Thoppe SR, Foukakis T, Lui WO, Wallin G, Hoog A, et al. Involvement of the PAX8/peroxisome proliferator-activated receptor gamma rearrangement in follicular thyroid tumors. J Clin Endocrinol Metab 2003;88:4440-5.

66. Hsiao SJ, Nikiforov YE. Molecular approaches to thyroid cancer diagnosis. Endocr Relat Cancer 2014;21:T301-13.

67. Xing M, Haugen BR, Schlumberger M. Progress in molecular-based management of differentiated thyroid cancer. Lancet 2013;381:1058-69.

68. Xing M, Alzahrani AS, Carson KA, Shong YK, Kim TY, Viola $\mathrm{D}$, et al. Association between BRAF V600E mutation and recurrence of papillary thyroid cancer. J Clin Oncol 2015; 33:42-50.

69. Tufano RP, Teixeira GV, Bishop J, Carson KA, Xing M. BRAF mutation in papillary thyroid cancer and its value in tailoring initial treatment: a systematic review and meta-analysis. Medicine (Baltimore) 2012;91:274-86.

70. Xing M, Alzahrani AS, Carson KA, Viola D, Elisei R, Bendlova $B$, et al. Association between BRAF V600E mutation and mortality in patients with papillary thyroid cancer. JAMA 2013;309:1493-501.

71. Kim TY, Kim WB, Song JY, Rhee YS, Gong G, Cho YM, et al. The BRAF mutation is not associated with poor prognostic factors in Korean patients with conventional papillary thyroid microcarcinoma. Clin Endocrinol (Oxf) 2005;63: 588-93.

72. Liu RT, Chen YJ, Chou FF, Li CL, Wu WL, Tsai PC, et al. No correlation between BRAFV600E mutation and clinicopathological features of papillary thyroid carcinomas in Taiwan. Clin Endocrinol (Oxf) 2005;63:461-6.

73. Ito Y, Yoshida H, Maruo R, Morita S, Takano T, Hirokawa M, et al. BRAF mutation in papillary thyroid carcinoma in a Japanese population: its lack of correlation with highrisk clinicopathological features and disease-free survival of patients. Endocr J 2009;56:89-97.

74. Nikiforova MN, Wald AI, Roy S, Durso MB, Nikiforov YE. Targeted next-generation sequencing panel (ThyroSeq) for detection of mutations in thyroid cancer. J Clin Endocrinol Metab 2013;98:E1852-60.

75. Calado RT, Young NS. Telomere diseases. N Engl J Med 2009;361:2353-65.
76. Eisenberg DT. An evolutionary review of human telomere biology: the thrifty telomere hypothesis and notes on potential adaptive paternal effects. Am J Hum Biol 2011;23:149-67.

77. Kim NW, Piatyszek MA, Prowse KR, Harley CB, West MD, Ho PL, et al. Specific association of human telomerase activity with immortal cells and cancer. Science 1994; 266:2011-5.

78. Shay JW, Bacchetti S. A survey of telomerase activity in human cancer. Eur J Cancer 1997;33:787-91.

79. Huang FW, Hodis E, Xu MJ, Kryukov GV, Chin L, Garraway LA. Highly recurrent TERT promoter mutations in human melanoma. Science 2013;339:957-9.

80. Horn S, Figl A, Rachakonda PS, Fischer C, Sucker A, Gast $A$, et al. TERT promoter mutations in familial and sporadic melanoma. Science 2013;339:959-61.

81. Vinagre J, Pinto V, Celestino R, Reis M, Populo H, Boaventura $\mathrm{P}$, et al. Telomerase promoter mutations in cancer: an emerging molecular biomarker? Virchows Arch 2014; 465:119-33.

82. Vinagre J, Almeida A, Populo H, Batista R, Lyra J, Pinto V, et al. Frequency of TERT promoter mutations in human cancers. Nat Commun 2013;4:2185.

83. Landa I, Ganly I, Chan TA, Mitsutake N, Matsuse M, Ibrahimpasic $\mathrm{T}$, et al. Frequent somatic TERT promoter mutations in thyroid cancer: higher prevalence in advanced forms of the disease. J Clin Endocrinol Metab 2013;98:E1562-6.

84. Liu X, Bishop J, Shan Y, Pai S, Liu D, Murugan AK, et al. Highly prevalent TERT promoter mutations in aggressive thyroid cancers. Endocr Relat Cancer 2013;20:60310.

85. Liu T, Wang N, Cao J, Sofiadis A, Dinets A, Zedenius J, et al. The age- and shorter telomere-dependent TERT promoter mutation in follicular thyroid cell-derived carcinomas. Oncogene 2014;33:4978-84.

86 Melo M, da Rocha AG, Vinagre J, Batista R, Peixoto J, Tavares $\mathrm{C}$, et al. TERT promoter mutations are a major indicator of poor outcome in differentiated thyroid carcinomas. J Clin Endocrinol Metab 2014;99:E754-65.

87. Liu R, Xing M. TERT promoter mutations in thyroid cancer. Endocr Relat Cancer 2016;23:R143-55.

88. Alzahrani AS, Alsaadi R, Murugan AK, Sadiq BB. TERT promoter mutations in thyroid cancer. Horm Cancer 2016;7: 165-77.

89. Kim TH, Kim YE, Ahn S, Kim JY, Ki CS, Oh YL, et al. TERT promoter mutations and long-term survival in patients with thyroid cancer. Endocr Relat Cancer 2016;23:813- 
23.

90. Alzahrani AS, Qasem E, Murugan AK, Al-Hindi HN, AlKhafaji $D$, Almohanna $M$, et al. Uncommon TERT promoter mutations in pediatric thyroid cancer. Thyroid 2016;26: 235-41.

91. Ballester LY, Sarabia SF, Sayeed H, Patel N, Baalwa J, Athanassaki I, et al. Integrating molecular testing in the diagnosis and management of children with thyroid lesions. Pediatr Dev Pathol 2016;19:94-100.

92. Onder S, Ozturk Sari S, Yegen G, Sormaz IC, Yilmaz I, Poyrazoglu S, et al. Classic architecture with multicentricity and local recurrence, and absence of TERT promoter mutations are correlates of BRAF (V600E) harboring pediatric papillary thyroid carcinomas. Endocr Pathol 2016; 27:153-61.

93. Oishi N, Kondo T, Nakazawa T, Mochizuki K, Inoue T, Kasai $\mathrm{K}$, et al. Frequent BRAF (V600E) and absence of TERT promoter mutations characterize sporadic pediatric papillary thyroid carcinomas in Japan. Endocr Pathol 2017;28:103-11.

94. Liu X, Qu S, Liu R, Sheng C, Shi X, Zhu G, et al. TERT promoter mutations and their association with BRAF V600E mutation and aggressive clinicopathological characteristics of thyroid cancer. J Clin Endocrinol Metab 2014;99: E1130-6.

95. Oishi N, Kondo T, Ebina A, Sato Y, Akaishi J, Hino R, et al. Molecular alterations of coexisting thyroid papillary carcinoma and anaplastic carcinoma: identification of TERT mutation as an independent risk factor for transformation. Mod Pathol 2017;30:1527-37.

96. George JR, Henderson YC, Williams MD, Roberts DB, Hei $\mathrm{H}$, Lai SY, et al. Association of TERT promoter mutation, but not BRAF mutation, with increased mortality in PTC. J Clin Endocrinol Metab 2015;100:E1550-9.

97. Vuong HG, Altibi AMA, Duong UNP, Hassell L. Prognostic implication of BRAF and TERT promoter mutation combination in papillary thyroid carcinoma: a meta-analysis. Clin Endocrinol (Oxf) 2017;87:411-7.

98. Hahn SY, Kim TH, Ki CS, Kim SW, Ahn S, Shin JH, et al. Ultrasound and clinicopathological features of papillary thyroid carcinomas with BRAF and TERT promoter mu- tations. Oncotarget 2017;8:108946-57.

99. Melo M, Gaspar da Rocha A, Batista R, Vinagre J, Martins MJ, Costa G, et al. TERT, BRAF, and NRAS in primary thyroid cancer and metastatic disease. J Clin Endocrinol Metab 2017;102:1898-907.

100. Liu R, Bishop J, Zhu G, Zhang T, Ladenson PW, Xing M. Mortality risk stratification by combining BRAF V600E and TERT promoter mutations in papillary thyroid cancer: genetic duet of BRAF and TERT promoter mutations in thyroid cancer mortality. JAMA Oncol 2017;3:202-8.

101. Kim TH, Ki CS, Hahn SY, Oh YL, Jang HW, Kim SW, et al. Ultrasonographic prediction of highly aggressive telomerase reverse transcriptase (TERT) promoter-mutated papillary thyroid cancer. Endocrine 2017;57:234-40.

102. Wang N, Liu T, Sofiadis A, Juhlin CC, Zedenius J, Hoog A, et al. TERT promoter mutation as an early genetic event activating telomerase in follicular thyroid adenoma (FTA) and atypical FTA. Cancer 2014;120:2965-79.

103. Xu B, Tuttle RM, Sabra MM, Ganly I, Ghossein R. Primary thyroid carcinoma with low-risk histology and distant metastases: clinicopathologic and molecular characteristics. Thyroid 2017;27:632-40.

104. Haugen BR, Alexander EK, Bible KC, Doherty GM, Mandel SJ, Nikiforov YE, et al. 2015 American Thyroid Association management guidelines for adult patients with thyroid nodules and differentiated thyroid cancer: the American Thyroid Association guidelines task force on thyroid nodules and differentiated thyroid cancer. Thyroid 2016;26:1-133.

105. Tuttle RM, Tala H, Shah J, Leboeuf R, Ghossein R, Gonen $M$, et al. Estimating risk of recurrence in differentiated thyroid cancer after total thyroidectomy and radioactive iodine remnant ablation: using response to therapy variables to modify the initial risk estimates predicted by the new American Thyroid Association staging system. Thyroid 2010;20:1341-9.

106. Kim TH, Ki CS, Kim HS, Kim K, Choe JH, Kim JH, et al. Refining dynamic risk stratification and prognostic groups for differentiated thyroid cancer with TERT promoter mutations. J Clin Endocrinol Metab 2017;102:1757-64. 